\title{
Simulation of fuel injection through a nozzle having different position of the spray holes
}

\author{
Mikhail G. Shatrov ${ }^{1}$, Valerii I. Malchuk ${ }^{1}$, Sergei D. Skorodelov ${ }^{1}$, Andrey Y. Dunin ${ }^{1}$, \\ Vladimir V. Sinyavski ${ }^{1}$, Andrey L. Yakovenko ${ }^{1}$ \\ ${ }^{1}$ Departement of Heat Engineering and Automotive Engines, \\ Moscow Automobile and Road Construction State Technical University (MADI)
}

\section{Article Info}

Received Feb $10^{\text {th }}, 2019$

\section{Keyword:}

Diesel fuel system

Nozzle with different

Positions of the spray holes

Injection characteristics

Fuel feed system

simulation

\begin{abstract}
In the article, a method of hydraulic calculation of working process of a diesel fuel feed system having a nozzle with different positions of its spray holes was investigated. A research of diesel engine injector nozzle design which had two groups of holes was carried out. Entering edges of the first group with the coefficient of flow $\mu_{h l}$ were located in the sack volume and entering edges of the second group (coefficient of flow $\mu_{h u}$ ) - on the locking taper surface of the nozzle body. The coefficients of flow $\mu_{h l}$ and $\mu_{h u}$ differ considerably and depend on the valve needle position. This enables to distribute rationally the injection quantity by injection holes taking into account operating conditions of the diesel engine and hence - by the combustion chamber zones.
\end{abstract}

\section{Corresponding Author:}

Andrey Y. Dunin, Departement of Heat Engineering and Automotive Engines, Moscow Automobile and Road Construction State Technical University (MADI), 64, Leningradsky prospect, Moscow, 125319, Russian Federation

Email: a.u.dunin@yandex.ru

\section{Introduction}

The development of engines with advanced energetic and ecological parameters demands the design of new variants of fuel feed systems for different models of diesel engines. In this connection, it is important to raise injection pressure up to 2000 bar and higher [7, 8], as well as to control the injection rate front shape [6, 10, 14] and fuel distribution in the combustion chamber [11, 12]. The desired fuel injection law at any operation mode of the engine is formed by variation of the control impulse duration $[6,10,13,15]$ and pressure in the common rail. It also depends on wave propagation originating in the high pressure line and having a considerable impact on the fuel injection process in case of a multistage injection [9].

For rational distribution of fuel by different zones in the combustion chamber, a conception of zonal mixture formation was offered in MADI [3]. The essence of the zonal mixture formation is rational supply and atomization of fuel by different zones of the combustion chamber. The number of these zones is equal to the number of injector nozzle holes. Also displacement of the injector in relation to the center of the combustion chamber is taken into account.

The zonal mixture formation may be realized practically in any model of diesel engine and requires sophistication of the injector nozzle design making it possible to solve the tasks set.

\section{Design of the correcting injector nozzle}

Figure 1 shows a possible design of a diesel injector nozzle which enables a uniform distribution of fuel in the combustion chamber zones and relative correction of the dynamics of injected sprays oriented to the different zones of the combustion chamber [1]. 


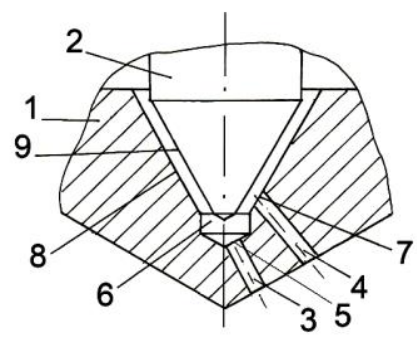

Figure 1. Injector nozzle diagram: 1 - injector nozzle body; 2 - needle valve; 3, 4-spray holes of the first (lower) and second (upper) groups; 5 - intake edges of the first group of spray holes in the sack volume; 6 sack volume; 7 - intake edges of the second group of spray holes on the locking cone; 8 -locking cone of the injector nozzle body seat; 9 - needle valve locking cone.

The injector nozzle consists of a body 1 (figure 1) and locking needle valve 2. It has two groups of spray holes -3 and 4. The inlet edges 5 of the holes of the first group 3 are located in the sack volume 6 and inlet edges 7 of the holes of the second group 4 - on the locking conical surface 8 of the injector nozzle body.

Research carried out in MADI [3] showed that coefficients of flow of the lower holes (3) $\mu_{h l}$ and of the upper holes (4) $\mu_{h u}$ differ considerably and depend on the position $y$ of the locking needle valve 2. At $y>0.2 \mathrm{~mm}, \mu_{h l}$ is larger than $\mu_{h u}$ by $10-20 \%$ and at $y<0.1 \mathrm{~mm}, \mu_{h l}$ is $2 \ldots 3$ times higher than $\mu_{h u}$. This enables to carry out directional correction the fuel supply by different zones of the diesel engine combustion chamber taking into account its operation conditions. At that, according to [1], the holes of the first group are directed to the remote walls of the combustion chamber located in the piston, and the holes of the second group - to the nearest zones. The design makes it possible to use more efficiently the air in the combustion chamber of the diesel engine, in which the injector is displaced in relation to the combustion chamber axis. This is shown in publication [1].

\section{Simulation model of the working process of the fuel feed system having a correcting injector nozzle}

Computational adaptation of the injector nozzle design to specific model of the diesel engine stipulates the use of a method and simulation program for calculation of the fuel equipment working process making it possible to estimate the injection characteristics that it provides.

Following is the method of calculation of diesel engine fuel feed system using a correcting injector nozzle developed in MADI [1].

The method of calculation of the Fuel Feed System (FFS) operation is based on the theory of unsteady flow of real fluid in the fuel line. At that, it is assumed that the fuel motion is one-dimensional and isothermal and its density and speed of impulse (wave) distribution are constant.

The following assumptions are taken when generating the equation of boundary conditions at the injector:

- at a certain time, the fuel pressure in any element of the FFS investigated is equal;

- friction of the needle valve along the guide orifice is negligibly low;

- yield of the injector elements is not taken into account;

- there are no wave propagation effects in the injector spring;

- dynamic component of the force acting on the needle valve is not taken into account;

- fuel property is constant;

- the gaseous phase is taken into account by way of a volume (not filled with fuel).

Computational scheme of the injector nozzle is shown in figure 2. 


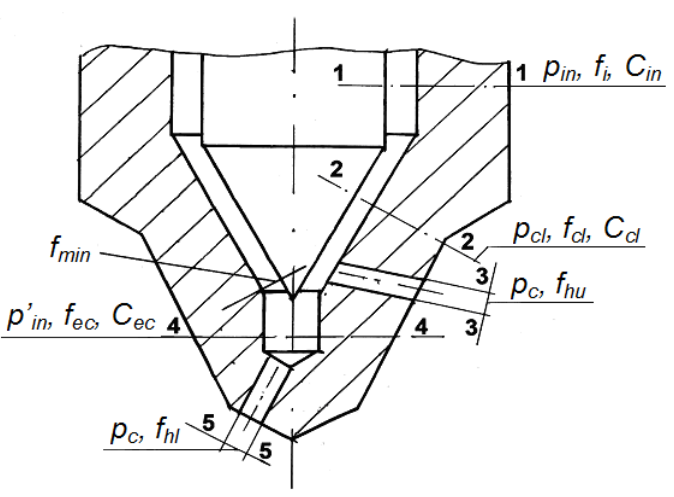

Figure 2. Computational scheme of the injector nozzle.

Under these assumptions, the equations of border conditions modeling hydrodynamic processes in the injector for the most common stages of the calculation are written as follows:

$$
\left\{\begin{array}{c}
\alpha_{i n} V_{i n} 6 n \frac{d p_{i n}}{d \varphi}=\left(f_{f p} c^{\prime}-\mu_{i n} f_{i n} \sqrt{\frac{2}{\rho}} \sqrt{p_{i n}-p_{c}}-\sigma_{3} f_{n v} c_{n v}-z_{3}\right) \sigma_{4} ; \\
6 n \frac{d V_{h l i n}}{d \varphi}=-\left(f_{f p} c^{\prime}-\sigma_{3} f_{n v} c_{n v}\right) \sigma_{4}^{\prime} ; \\
M 6 n \frac{d c_{n v}}{d \varphi}=\left[\left(f_{n v}-f_{n v}^{\prime}\right)\left(p_{i n}-p_{i n 0}\right)+\left(f_{n v}^{\prime}-f_{e c}\right) p_{c l}+f_{e c} p_{i n}^{\prime}-\delta^{\prime} y\right] \sigma_{3} ; \\
6 n \frac{d y}{d \varphi}=c_{n v} \sigma_{3} ; \\
\left\{\begin{array}{c}
Q_{i n}=\mu_{i n} f_{i n} \sqrt{\frac{2}{\rho}\left(p_{i n}-p_{c}\right)} ; \\
p_{c l}=p_{i n}-\frac{\rho Q_{i n}^{2}}{2\left(\mu_{c l} f_{c l}\right)^{2}} ; \\
p_{c l l}=p_{c l}+\frac{\rho Q_{i n}^{2}}{2 f_{c l}^{2}} ; \\
Q_{h u}=\mu_{h u} f_{h u} \sqrt{\frac{2}{\rho}\left(p_{c l l}-p_{c}\right)} \\
Q_{h l}=Q_{i n}-Q_{h u} ; \\
p_{s v}=\frac{\rho Q_{h l}^{2}}{2\left(\mu_{h} f_{h}\right)^{2}}+p_{c} ; \\
p_{i n}^{\prime}=p_{s v}-\frac{\rho Q_{h l}^{2}}{2\left(f_{e c} \varepsilon_{e c}\right)^{2}} .
\end{array}\right.
\end{array}\right.
$$

The following legend is used in systems (1) and (2) and further on: $c_{n v}$ - injector nozzle valve speed; $c, c^{\prime}-$ fuel speed at the inlet to the fuel pipe and outlet from it; $d_{f p}$ - diameter of the fuel pipe channel; $f_{n v}, f_{h}$ - area of the needle valve along its axle and area of the injector nozzle spray holes; $f_{n v}$ - area limited by the locking edge of the needle valve; $f_{f p}$ - cross section area of the fuel pipe channel; $M$ - masses of injector moving parts; $p_{i n}, p_{i n 0}$ - fuel pressure in the injector: current value and at the time of needle valve motion start; $p_{i n,} p_{c l}-$ current pressure at the inlet to the spray holes of the injector nozzle in the clearance between the locking cones of the needle valve and injector nozzle body, as well as in the sack volume; $p_{s v}, p_{c l}$-delivery head upstream the spray holes in the sack volume and in the clearance between the locking cones of the needle valve and injector; $p_{c}$ - current pressure in the diesel engine cylinder; $V_{\text {in }}$ - fuel volume contained in the injector; $y, y_{\text {мах }}$ - current and maximal needle valve lift; $\delta^{\prime}$-stiffness of the delivery valve spring and injector spring; $\alpha, \rho, v-$ coefficient of compressibility, density and kinematic viscosity of fuel; $\mu_{c l}$ - coefficient of flow in the clearance between the locking cones of the injector nozzle; $\mu_{h l}, \mu_{h u}$ - coefficients of flow of the spray holes of the first (lower) and second (upper) groups of the injector nozzle correspondingly; $\mu_{h l} f_{h l}, \mu_{h u} f_{h u}, \mu_{i n} f_{i n}$ - equivalent flow areas of spray holes of the first and second groups and of the injector nozzle assembled; $\varphi_{c}-$ fuel pump 
camshaft turning angle; $z_{3}$ - flow rate through the clearance between the needle valve and the injector nozzle body.

The first equation of the system (1) is a equation of the volume balance in the injector nozzle cavity. This equation is solved if there is no rupture of integrity. If integrity was not restored, a second equation [5] is used. The order of using these two equations is defined by step functions $\sigma_{4}$ и $\sigma_{4}^{\prime}$ :

$$
\begin{aligned}
& \sigma_{4}=0 \text { and } \sigma_{4}^{\prime}=1 \text { at } V_{h l i n}^{\prime} \geq 0 \text { and } p_{\text {in }}^{\prime}=0 ; \\
& \sigma_{4}=1 \text { and } \sigma_{4}^{\prime}=0 \text { at } V_{h l i n}^{\prime}=0 \text { and } p_{\text {in }}^{\prime}>0 .
\end{aligned}
$$

The third equation of the system (1) is the dynamic balance of the needle valve in the form of [3]. The inertial force of the needle is set equal to the sum of the forces of fuel and spring applied to the needle. The step function $\sigma_{3}=0$ if the needle valve is on the seat (or on the rest) and the resulting force applied to the needle valve (the force $F_{n v}$ ) presses the needle valve to the seat (or to the rest), i.e. $\sigma_{3}=0$ at $y=0$ and $F_{n v}<0$ or at $y=$ $y_{\text {Max }}$ and $F_{n v}>0 ; \sigma_{3}=1$ in all other cases.

Dependencies of flows $Q_{i n}, Q_{h l}, Q_{h u}$ through the injector on pressures $p_{i n}, p_{s v}, p_{i n}^{\prime}, p_{c l}, p_{c l l}$ are shown in the system (2). At that, it is taken into consideration that calculated dependencies of $\mu_{i n} f_{i n} \mu_{c l}, \varepsilon_{e c}, \mu_{h l}, \mu_{h u}, f_{c l}, f_{\min }$, $f_{e c}, f_{\text {in }}$ on the needle valve position $y$ are known.

Calculation of $\mu_{i n} f_{\text {in }}$ is carried out by the system of equations [3, 4]:

$$
\left\{\begin{array}{c}
\frac{1}{\left(\mu_{i n} f_{i n}\right)^{2}}=\frac{1}{\left(\mu_{c l} f_{c l}\right)^{2}}+\frac{1}{\left(\mu_{h u} f_{h u}+\mu_{m h l} f_{m h l}\right)^{2}}-\frac{1}{f_{c l}^{2}} \\
\frac{1}{\left(\mu_{m h l} f_{m h l}\right)^{2}}=\frac{1}{\left(\mu_{m} f_{m}\right)^{2}}+\frac{1}{\left(\mu_{h l} f_{h l}\right)^{2}}-\frac{1}{\left(\varepsilon_{e c} f_{e c}\right)^{2}} .
\end{array}\right.
$$

Calculation of $f_{\min }=f(y)$ and $f_{c l}=f(y)$ is carried out by the method of MADI [4].

The minimal cross-section area $f_{\min }$ in the clearance between the locking cones of the needle valve and the seat is estimated as the area of the lateral surface of the truncated cone with the generating line $S_{z h}$. At that, the generating line $S_{z h}$ is perpendicular to the bisector between angles $\beta_{n v}$ and $\beta_{i n}$, i.e. perpendicular to the flow line of the working fluid (figure 3 ). Than

$$
f_{\text {min }}=0,5 \pi\left(d_{s v}+d_{n v l}\right) S_{z h},
$$

where $d_{s v}$ and $d_{n v l}$ - diameters indicated in figure 3 .

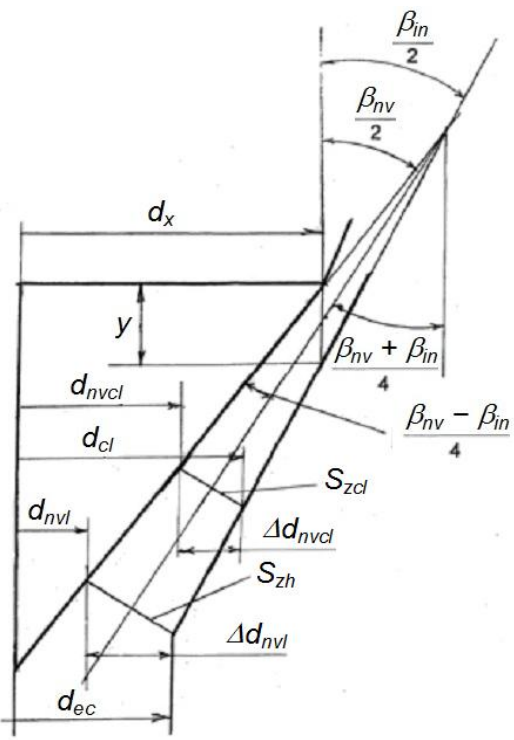

Figure 3. Scheme of clearance between the locking cones of the needle valve and the seat.

$$
\begin{gathered}
d_{n v l}=d_{e c}-2 \Delta d_{n v l}, \\
\Delta d_{n v l}=S_{z h} \cos \left(\frac{\beta_{n v}+\beta_{i n}}{4}\right), \\
S_{z h}=\left[\sin \left(\frac{\beta_{n v}}{2}\right) / \cos \left(\frac{\beta_{n v}-\beta_{i n}}{4}\right)\right]\left[y+\frac{d_{x}-d_{e c}}{2}\left(\operatorname{ctg}\left(\frac{\beta_{i n}}{2}\right)-\operatorname{ctg}\left(\frac{\beta_{n v}}{2}\right)\right)\right] .
\end{gathered}
$$


Calculation of the dependence $f_{c l}=\mathrm{f}(y)$ is carried out by indicated formulas (4) and (5) but on condition that $d_{s v}$ is $d_{c l} ; d_{n v l}$ is $d_{n v c l} ; \Delta d_{n v l}$ is $\Delta d_{n v c l}$. In this publication, $d_{c l}$ - is an average value of $d_{x}$ and $d_{s v}$.

Experiments show that coefficients $\mu_{c l}, \mu_{\min }$ and $\varepsilon_{s v}$ have quite certain values and depend on the design of the injector nozzle, flow conditions and the needle valve position. In this way, for the needle valves of the Noginsk Fuel Equipment Factory, the following empiric formulas for determining $\mu_{c l}, \mu_{m i n}, \varepsilon_{s v}$ were obtained [3]:

$$
\begin{gathered}
\mu_{c l}=0,573\left(1-\frac{f_{c l}}{f_{i}}\right)^{-1,53} \overline{\operatorname{Re}}_{\kappa \phi} 0,32 ; \\
\mu_{\min }=1,439\left(\frac{f_{\min }}{f_{e c}}\right)^{0,25} ; \\
\varepsilon_{e c}=0,815\left(\frac{f_{\min }}{f_{e c}}\right)^{0,25}
\end{gathered}
$$

In (6) and further on, $\overline{\operatorname{Re}}_{c l}=\frac{\operatorname{Re}_{c l}}{2300}$.

The Reynolds number in the clearance between the locking cones of the needle valve and the seat are calculated by formulas [5]:

$$
\begin{gathered}
\operatorname{Re}_{c l}=\frac{4 R_{g} c_{c l}}{v} ; \\
R_{g}=\frac{f_{c l}}{\Pi} ; \\
\Pi=\pi\left(d_{c l}+d_{n v c l}\right) .
\end{gathered}
$$

\section{Results of calculated and experimental research}

The foregoing method of modeling was realized in the simulation model of hydrodynamic calculation of the FFS working process.

The model approbation was carried out on the base of the FFS of the V8 diesel engine having D/S=110/115. The FFS investigated was equipped with the A-size Bosh fuel pump and prototype injector nozzle (figure 1) manufactured by the Noginsk Fuel Equipment Factory.

Experimental hydraulic characteristics of the injector are presented in figure 4.

A specific feature of the hydraulic characteristics of the correcting injector (figure 1) is that at partial lifts, the through capacity of the spray holes of the second group is $2 \ldots 3$ times lower than that of the first group. When the needle valve lift $(y)$ increases, the values of $\mu_{h l}$ and $\mu_{h u}$ become closer and differ by $20 \ldots 25 \%$.

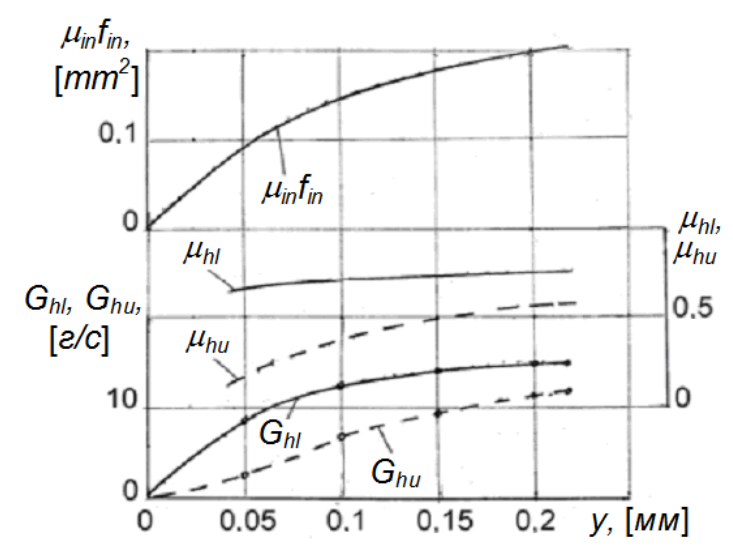

Figure 4. Hydraulic characteristics of the injector nozzle.

The results of comparison of calculated and experimental injection characteristics of the FFS investigated are shown in figure 5 . 


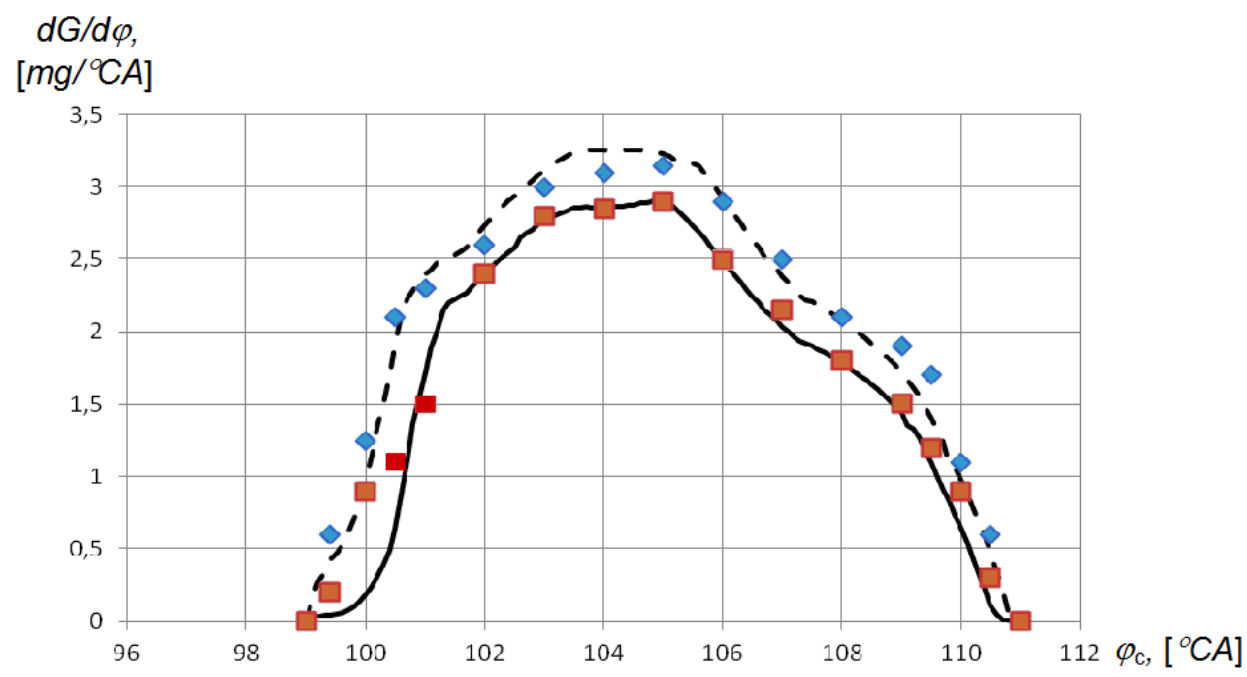

Figure 5. Injection characteristics of the FFS of the diesel engine V8 having D/S=110/115 with correcting injector nozzle $\left(n_{c}=1400 \mathrm{rpm}, q_{i n j}=58 \mathrm{~mm}^{3}\right)$ : - - experiment for the spray holes of the first and second groups correspondingly, _ _ _ _ _ _ - calculation for the spray holes of the first and second groups correspondingly

Experimental research of the injection characteristics was carried out at the following conditions: the high pressure fuel pump camshaft speed $n_{c}=1400 \mathrm{rpm}$, fuel rate $q_{i n j}=58 \mathrm{~mm}^{3}$.

The results presented in figure 5 demonstrate that the model developed assures close values of simulation results and experimental data.

Comparison of calculated and experimental data has also demonstrated that in the initial injection period, the rate of fuel supply rise in the combustion chamber of the diesel engine from the spray holes of the first group is $1.5 \ldots 2$ times higher than that from the holes of the second group. At that, fuel injection rates via the holes of the first group exceed the injection rates from the holes of the second group by $20 \%$.

In such a way, prerequisites are created for a more efficient use of air in the diesel engines including those in which the injector is mounted not symmetrically in respect to the combustion chamber axis. This promotes improvement of fuel efficiency, decrease of combustion process dynamics and the amount of toxic components in the exhaust gases as was shown in earlier works [3].

\section{Conclusions}

1. The method of hydrodynamic calculation of the working process of the fuel feed system with correcting injector nozzle demonstrated good agreement with the results of experimental investigations of the prototype injector nozzle.

2. Implementation of the calculation method developed for perfection of the working processes of diesel engines in which the injector is mounted not symmetrically in respect to the combustion chamber axis enables to decrease considerably its duration and raise the efficiency of the diesel engine working process.

\section{References}

[1] N. S. Alekhin, I. N. Kurzel', V. I. Mal'chuk, A. A. Mukharski, V. I. Trusov, M. K. Skudnov, Patent 922302 SSSR MKI F02M 23/06, 23.04.1982.

[2] I. V. Astakhov, L. N. Golubkov, V. I. Trusov, A. S. Khachiian, L. M. Riabkin, "Fuel systems and efficiency of diesels," Mashinostroenie, Moscow, 1990, 288 p.

[3] V. I. Malchuk, "Fuel injection and zonal mixture formation," MADI, Moscow, 2009, $176 \mathrm{p}$.

[4] V. I. Malchuk, S. D. Skorodelov, "Hydraulic calculation of diesel nozzles, wherein the location of the spray holes," Vestnik MADI, 2013, no 4 (35), pp. 31-37.

[5] B. B. Nekrasov, "Hydraulics," Mashinostroenie, Moscow, 1969, 264 p.

[6] M. G. Shatrov, L. N. Golubkov, A. U. Dunin, P. V. Dushkin, A. L. Yakovenko, "The new generation of common rail fuel injection system for Russian locomotive diesel engines," Pollution Research, Volume 36 (3), 2017, pp. 678-684. 
[7] M. G. Shatrov, L. N. Golubkov, A. U. Dunin, A. L. Yakovenko, P. V. Dushkin, "Influence of high injection pressure on fuel injection perfomances and diesel engine worcking process," Thermal Science, Volume 19, Number 6, 2015, pp. 2245-2253.

[8] M. G. Shatrov, L. N. Golubkov, A. U. Dunin, A. L. Yakovenko, P. V. Dushkin, "Research of the impact of injection pressure 2000 bar and more on diesel engine parameters," International Journal of Applied Research, Volume 10, Number 20, 2015, pp. 41098-41102.

[9] M. G. Shatrov, L. N. Golubkov, A. U. Dunin, A. L. Yakovenko, P. V. Dushkin, "Experimental research of hydrodynamic effects in common rail fuel system in case of multiple injection," International Journal of Applied Engineering Research, Volume 11, Number 10, 2016, pp. 6949-6953.

[10] M. G. Shatrov, L. N. Golubkov, A. Yu. Dunin, P. V. Dushkin, A. L. Yakovenko, "A method of control of injection rate shape by acting upon electromagnetic control valve of common rail injector," International Journal of Mechanical Engineering and Technology, Volume 8, Issue 11, 2017, pp. 676-690.

[11] M. G. Shatrov, V. I. Malchuk, A. U. Dunin, A. L. Yakovenko, "The influence of location of input edges of injection holes on hydraulic characteristics of injector the diesel fuel system," International Journal of Applied Engineering Research, Volume 11, Number 20, 2016, pp. 10267-10273.

[12] M. G. Shatrov, V. I. Malchuk, A. Y. Dunin, I. G. Shishlov, V. V. Sinyavski, "A control method of fuel distribution by combustion chamber zones and its dependence on injection conditions," Thermal Science, Volume 22, Number 5, 2018, pp 1425-1434.

[13] M. G. Shatrov, V. V. Sinyavski, A. Y. Dunin, I. G. Shishlov, A. V. Vakulenko, "Method of conversion of high- and middle-speed diesel engines into gas diesel engines," Facta Universitatis. Series: Mechanical Engineering, Vol. 15, No 3, 2017, pp. 383-395.

[14] M. G. Shatrov, V. V. Sinyavski, A. Y. Dunin, I. G. Shishlov, A. V. Vakulenko, A. L. Yakovenko, "Using simulation for development of the systems of automobile gas diesel engine and its operation control," International Journal of Engineering and Technology, №7 (2.28), 2018, pp. 288-295.

[15] V. V. Sinyavski, I. V. Alekseev, I. Y. Ivanov, S. N. Bogdanov, Y. V. Trofimenko, "Physical simulation of high- and medium-speed engines powered by natural gas," Pollution Research, Vol. 36 (3), 2017, pp. 684-690. 